\title{
DESARROLLO DEL PAISAJE HOLOCENO EN LA CUENCA DE EL BOLSÓN: GENTE Y AMBIENTE EN PROCESOS DE CAMBIO Y ESTABILIDAD
}

\author{
HOLOCENE LANDSCAPE DEVELOPMENT IN THE EL BOLSON BASIN: \\ PEOPLE, ENVIRONMENT, AND PROCESSES OF CHANGE AND STABILITY
}

\author{
Julio Kulemeyer ${ }^{a}$, Liliana Lupo ${ }^{b}$, M. Carolina Madozzo Jaén ${ }^{c}$, Alicia Cruz ${ }^{d}$, \\ Patricia Cuenya ${ }^{e}$, Mariana Malobertif, Gabriel Cortés ${ }^{g}$ y Alejandra Korstanje ${ }^{h}$
}

\begin{abstract}
El valle de El Bolsón (Departamento de Belén, Catamarca, Argentina) tiene una larga historia de ocupaciones, sobre todo desde el inicio de la agricultura hasta la actualidad. Se presenta una primera integración local interdisciplinaria, utilizando diferentes proxies (sedimentos, suelos, mamíferos, polen y otros microfósiles) para contribuir a la primera discusión de los procesos de estabilidad y cambio en la historia social, paleoclimática y el medio ambiente en el valle durante el Holoceno. En tal sentido, observamos importantes cambios ambientales durante el Holoceno Tardío, que se manifiestan en forma de procesos de acumulación y erosión, cambios de uso del suelo e influencia antropogénica sobre los frágiles ecosistemas semiáridos en el contexto de las variaciones paleoclimáticas.
\end{abstract}

Palabras claves: cambio ambiental, paisajes agrarios, interdisciplina.

The Valley of El Bolsón (Department Belén, Catamarca, Argentina) has a long history of occupations, mainly since the beginning of agriculture until today. We present a first local interdisciplinary integration using different proxies (sediments, soils, mammals, pollen and other microfossils), to contribute to the first discussion of the processes of stability and change in social history, paleoclimate and environment in the valley during the Holocene. We observed significant environmental changes during the Late Holocene, which manifest in the form of accumulation and erosion processes and changes in land use and anthropogenic influence on the fragile semi-arid ecosystems in the context of paleoclimatic variations.

Key words: environmental change, Agricultural landscapes, interdisciplinary.

\section{Introducción}

Los antecedentes regionales han permitido abordar parcialmente la problemática del vínculo entre los cambios del paisaje y las poblaciones prehispánicas en las regiones áridas y semiáridas del NOA (por ejemplo, Kulemeyer, 2005; Morales et al., 2009) y cómo los nuevos escenarios, generalmente con una progresiva impronta cultural, modificaron su capacidad de sostener a las poblaciones que lo habitaban.
El Valle de El Bolsón, ubicado en el Departamento Belén, Catamarca, Argentina (con extremos al norte de $26^{\circ} 48^{\prime} \mathrm{S}, 66^{\circ} 43^{\prime} \mathrm{O}$ y de $27^{\circ} 06^{\prime} \mathrm{S}, 66^{\circ} 50^{\prime} \mathrm{O}$ al Sur, Figura 1), presenta actualmente condiciones definidas por su ubicación en el límite de las sierras pampeanas noroccidentales y la puna austral y una historia de ocupaciones principalmente desde el Período Agroalfarero a la actualidad. Este trabajo tiene por objetivo aportar a la discusión sobre las interrelaciones entre las poblaciones prehispánicas y el ambiente durante el Holoceno en el citado valle.

a Universidad Nacional de Jujuy, INTEMI (FI, UNJu) - CIT (CONICET-UNJu), Argentina. Correo electrónico: jjkulemeyer@ fi.unju.edu.ar

b Universidad Nacional de Jujuy, (FCA, UNJu) - CIT (CONICET-UNJu), Argentina. Correo electrónico: lupoli@ imagine. com.ar

c Instituto Superior de Correlación Geológica (CONICET), Argentina. Correo electrónico: cmadozzo@ yahoo.com.ar

d Universidad Nacional de Jujuy, (FCA, UNJu), Argentina. Correo electrónico: ali49c@ hotmail.com

e Universidad Nacional de Tucumán, (FCNeIML, UNT), Argentina. Correo electrónico: patycuenya53@ hotmail.com

f Instituto de Arqueología y Museo (FCNeIML, UNT), Instituto Superior de Estudios Sociales (CONICET-UNT), Argentina. Correo electrónico: marianamaloberti@yahoo.com.ar

g Universidad Nacional de Jujuy, INTEMI (FI, UNJu), Argentina. Correo electrónico: rgcortes@ yahoo.com.ar

h Instituto de Arqueología y Museo (FCNeIML, UNT), Instituto Superior de Estudios Sociales (CONICET-UNT), Argentina. Correo electrónico: alek@webmail.unt.edu.ar 

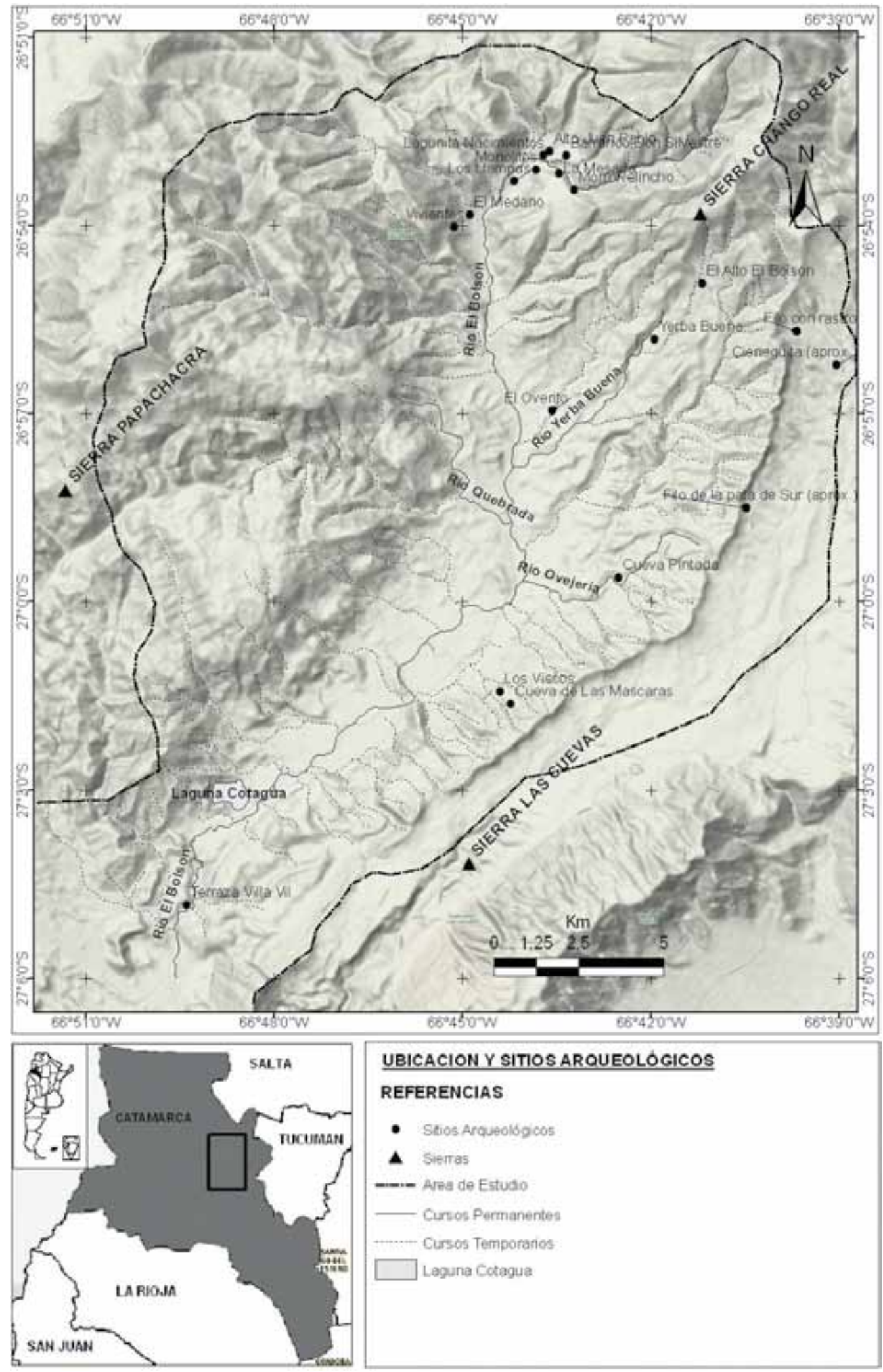

\section{UBICACION Y SITIOS AROUEOLOGICOS} REFERENCIAS

- Stios Arqueollogicos

A Siemas

-.- Area de Estudio

Cursos Permanentes

Cursos Temporanios

Laguna Cotagua

Figura 1. Ubicación del área de estudio y de los sitios arqueológicos. 


\section{Planteo del problema}

Iniciamos las investigaciones en el Valle de El Bolsón como equipo de trabajo dedicado a la agroarqueología, considerando importante conocer los modos en los cuales la organización de la vida doméstica y comunitaria de las poblaciones locales se relacionó con los cambios sociopolíticos y ambientales que se produjeron en el área. Para su abordaje hemos ido desarrollando una serie de instrumentos y metodologías que nos permitieran abordar la historia del paisaje agrario prehispánico en un sentido integral (Korstanje, 2005; Korstanje, y Cuenya 2008 y 2010; Quesada y Korstanje, 2010; Maloberti, 2012). Concretamente, las investigaciones han permitido conocer una variedad de aspectos de las actividades campesinas prehispánicas novedosas para la arqueología de la región. Se han documentado asentamientos agroganaderos formativos con diferencias en la disposición espacial, así como también en las técnicas agrícolas empleadas, que incluyen diferencias en las taxa cultivadas, uso y abonado del suelo y sistemas de regadío (Korstanje, 2005). Tal situación muestra que no es posible continuar considerando la historia agraria en términos tan homogéneos como suelen hacer en general los esquemas de desarrollo arqueológico (Quesada y Korstanje, 2010). Por ello, nuestra hipótesis es que la historia del campesinado de los valles altos del oeste catamarqueño presenta ciertas particularidades locales que no han sido consideradas por los modelos arqueológicos y ambientales regionales. Los esquemas clásicos han marcado diferencias en modos de hacer y llevar adelante la vida productiva en distintos momentos de la historia prehispánica en el NOA, que no son necesariamente observados a nivel local.

Si bien nuestro abordaje de la agricultura antigua incorpora instrumentos de análisis principalmente arqueológicos, el estudio de los paisajes agrarios y de la agricultura en sí misma implica una comprensión más profunda de las condiciones ambientales en el pasado y los motivos y formas que fueron modelando el paisaje actual, por lo que consideramos que las variables ambientales y las sociales no pueden ser estudiadas separadamente en este tema. Es por ello que uno de los problemas que debimos abordar es el estudio de la historia ambiental de un modo interdisiciplinario, pero por sobre todo buscando desarrollar también una metodología que nos permita calibrar con la mayor precisión posible los eventos de crisis, cambios y estabilidades agrícolas
(Korstanje, 2011). Esto es, una historia del ambiente holocénico local intentando correlacionar eventos de cambio y estabilidad que puedan ser puestos en diálogo con el registro arqueológico y no separado de él. Para ello es necesario primero identificar las variables ambientales en distintas escalas de tiempo-espacio y su relación con las condiciones de vida de la población y las pautas productivas locales desarrolladas.

\section{Importancia de la investigación}

Para conocer estas transformaciones y continuidades, aplicamos un abordaje que integra el estudio del paisaje, arqueología de la agricultura y un análisis desde las ciencias del ambiente para caracterizar los ambientes actuales y los paleoambientes. En definitiva, pretendemos aportar desde las ciencias del pasado al conocimiento y valorización de las antiguas prácticas campesinas en espacios productivos, así como su incidencia en las modificaciones del paisaje mismo.

Una de las mayores dificultades que presenta este abordaje es homogeneizar las escalas de tiempo y espacio con que las distintas disciplinas realizan sus análisis. Cada una de las disciplinas maneja sus propias escalas y es difícil adaptarlas a los requerimientos del problema arqueológico planteado. No obstante esta limitación, hemos desarrollado y discutido metodológicamente las posibilidades que nos dan los diferentes proxies analizados y puestos en juego para la discusión. Justamente por su ductilidad para la resolución temporal fina a la que aspiramos, es que hemos elegido proxies vegetales que pueden caracterizar ambientes y actividades antrópicas (principalmente polen, fitolitos y almidones, aunque también estamos trabajando con diatomeas, crisofíceas y microcarbones), fauna de sensibilidad ambiental marcada (como los roedores sigmodontinos), y el estudio sensible de suelos, sedimentos y marcadores geomorfológicos, integrándolos con dataciones radiocarbónicas en los casos que fue posible fechar eventos.

\section{Métodos}

La presente investigación se aborda desde una perspectiva interdisciplinaria, necesaria para comprender las relaciones mutuas que se dieron en el pasado entre la gente y su entorno, con un adecuado control cronológico (Tabla 1). Para ello se cuenta con antecedentes previos de estudios del equipo, tanto 
Tabla 1: Listado de fechados radiocarbónicos utilizados

\begin{tabular}{|c|c|c|c|c|}
\hline Muestra & $\begin{array}{c}\text { Nro. } \\
\text { Laboratorio }\end{array}$ & Edad años a.P. & Edad años cal a.P. & $\begin{array}{l}\text { Edad años cal } \\
\text { a.d./a.C. (media) }\end{array}$ \\
\hline Morro Relincho & LP 899 & $270 \pm 60$ & $309 \pm 118$ & 1641 cal a.d. \\
\hline Laguna Cotagua (16-18) & AA89446 & $345 \pm 59$ & $404 \pm 67$ & 1546 cal a.d. \\
\hline La Angostura & LP 2058 & $390 \pm 70$ & $421 \pm 75$ & 1529 cal a.d. \\
\hline La Angostura & LP 2219 & $440 \pm 60$ & $447 \pm 76$ & $1503 \mathrm{cal}$ a.d. \\
\hline Los Viscos & UGA\# 7975 & $530 \pm 60$ & $575 \pm 50$ & 1375 cal a.d. \\
\hline Morro Relincho & UGA\# 8358 & $550 \pm 40$ & $582 \pm 44$ & 1368 cal a.d. \\
\hline Cueva de las Máscaras 2 & LP-2297 & $720 \pm 70$ & $657 \pm 67$ & 1293 cal a.d. \\
\hline Alto Juan Pablo & AA88346 & $755 \pm 81$ & $711 \pm 64$ & 1239 cal a.d. \\
\hline Los Viscos & UGA\# 9071 & $790 \pm 40$ & $718 \pm 26$ & 1232 cal a.d. \\
\hline Terraza Villa Vil & AA88343 & $818 \pm 36$ & $736 \pm 32$ & 1214 cal a.d. \\
\hline Los Viscos & LP 877 & $820 \pm 50$ & $747 \pm 43$ & 1203 cal a.d. \\
\hline Cueva de las Máscaras 3 & LP-2300 & $810 \pm 90$ & $777 \pm 87$ & 1173 cal a.d. \\
\hline Cueva de las Máscaras 4 & LP-2301 & $830 \pm 90$ & $789 \pm 88$ & 1161 cal a.d. \\
\hline Los Viscos & UGA\# 8362 & $940 \pm 40$ & $858 \pm 50$ & 1092 cal a.d. \\
\hline Cueva de las Máscaras 5 & LTL1161A & $971 \pm 35$ & $876 \pm 49$ & 1074 cal a.d. \\
\hline Los Viscos & UGA\# 8363 & $1002 \pm 43$ & $899 \pm 56$ & $1051 \mathrm{cal}$ a.d. \\
\hline Barranco Don Silvestre & LP 1284 & $1060 \pm 50$ & $992 \pm 49$ & 958 cal a.d. \\
\hline Terraza Villa Vil & AA88344 & $1111 \pm 34$ & $1019 \pm 36$ & $931 \mathrm{cal}$ a.d. \\
\hline El Alto El Bolsón & UGA\# 9065 & $1120 \pm 40$ & $1029 \pm 44$ & $921 \mathrm{cal}$ a.d. \\
\hline Los Viscos & UGA\# 7974 & $1120 \pm 50$ & $1044 \pm 62$ & 906 cal a.d. \\
\hline Lagunita Nacimientos & AA88345 & $1391 \pm 36$ & $1316 \pm 20$ & $634 \mathrm{cal}$ a.d. \\
\hline Laguna Cotagua (590-591) & AA89447 & $1420 \pm 58$ & $1340 \pm 38$ & $610 \mathrm{cal}$ a.d. \\
\hline La Mesada & LP 911 & $1520 \pm 90$ & $1433 \pm 84$ & 517 cal a.d. \\
\hline Cueva Pintada & LP 1262 & $1790 \pm 80$ & $1717 \pm 97$ & $233 \mathrm{cal}$ a.d. \\
\hline Cueva de las Máscaras 7 & NSRL-10737 & $1880 \pm 35$ & $1763 \pm 43$ & $187 \mathrm{cal}$ a.d. \\
\hline Los Viscos Capa 4 & UGA\# 7973 & $2270 \pm 230$ & $2316 \pm 296$ & 366 cal a.C. \\
\hline Laguna Cotagua (870-875) & LTL4411A & $5581 \pm 40$ & $6365 \pm 38$ & 4415 cal a.C. \\
\hline
\end{tabular}

del tipo agroarqueológico (Korstanje y Cuenya, 2008 y 2010; Quesada y Korstanje, 2010; Quesada y Maloberti, 2010; Korstanje, 2011; Maloberti, 2012), como paleoecológicos del Holoceno (Madozzo Jaén, 2009; Sánchez et al., 2010; Cruz et al., 2011, Ortiz et al., 2012), a los que se aportan nuevas evidencias obtenidas del estudio de secuencias de terrazas holocenas expuestas, lagunas temporarias y mapeos geológicos y geomorfológicos. Se deriva al lector a la bibliografía citada para la descripción de las metodologías específicas, ya que al ser varias disciplinas, sería muy extenso explicar aquí a cada una de ellas.

A lo expuesto se agrega en esta contribución la realización de dos perforaciones en lagunas temporarias ubicadas a nivel del río El Bolsón, en las lagunas Chica y Cotagua, mediante sondeos mecánicos con un percutor, alcanzando profundidades de 5 y $9 \mathrm{~m}$, respectivamente. Dichas lagunas, ubicadas en el sector central del valle, fueron seleccionadas por ofrecer, a priori, la posibilidad de contar con registros continuos de los paleoambientes del Holoceno. Luego de un primer análisis se seleccionó el testigo más profundo (laguna Cotagua) para ser estudiado inicialmente, el que fue objeto de análisis radiocarbónico, textura y polen.

\section{Ambiente actual}

\section{Geología}

La geología del área de trabajo está representada por una columna estratigráfica relativamente reducida en cuanto a número de formaciones, pero no en cuanto a espesores de las mismas (Turner, 1973). El basamento está constituido por sedimentos polimícticos metamorfizados (Formación Loma Corral) e inyectados (Formación Chango Real). Sobre el mismo, apoyan discordantemente sedimentos continentales del Terciario (Grupo El Bolsón) y acarreos del Cuaternario y una cobertura eólica del Holoceno Superior (Figura 2).

Las rocas asignadas al Precámbrico se encuentran en el sector norte y oeste del área de estudio. La Formación Loma Corral está integrada por rocas metamórficas (esquistos, pizarras y filitas), en las que predominan las tonalidades verdosas. La 

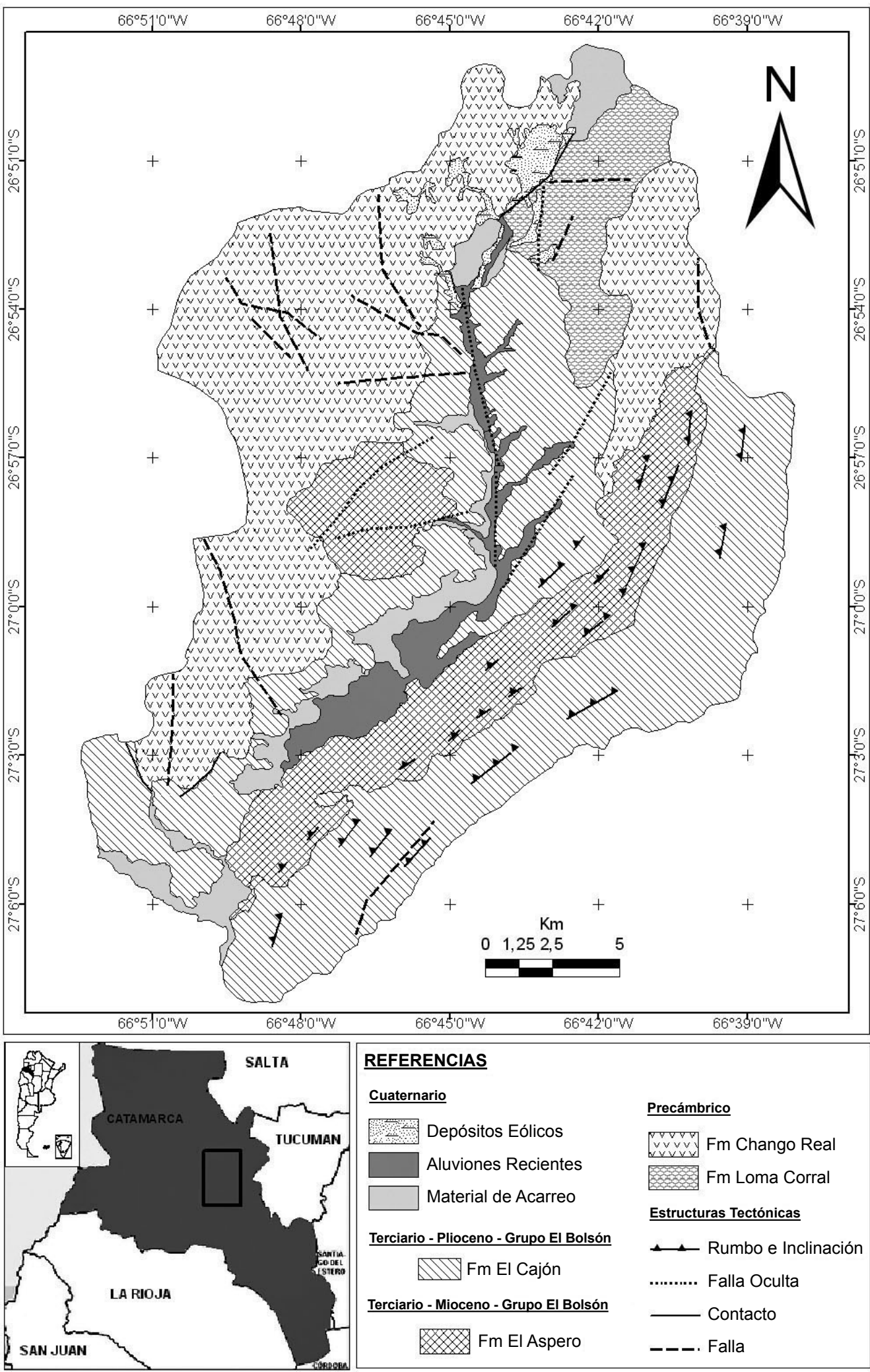

\section{REFERENCIAS \\ Cuaternario \\ Depósitos Eólicos \\ Aluviones Recientes \\ $\square$ Material de Acarreo}

Terciario - Plioceno - Grupo El Bolsón

MIVFm El Cajón

Terciario - Mioceno - Grupo El Bolsón

Fm El Aspero
Precámbrico

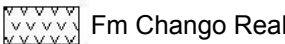

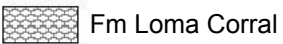

Estructuras Tectónicas

ــ Rumbo e Inclinación Falla Oculta Contacto

Falla

Figura 2. Mapa geológico del área de estudio. 
Formación Chango Real está constituida por granitos migmatíticos, vale decir, es un complejo integrado por sedimentos metamorfizados con abundante penetración ígnea, en el sector occidental y norte de la cuenca de El Bolsón.

Sobre el basamento se apoya la cubierta sedimentaria cenozoica. Los sedimentos más antiguos son del Terciario y corresponden al Calchaquense y Araucanense; dentro del Cuaternario se encuentran diversos acarreos y materiales eólicos recientes. El Grupo El Bolsón presenta materiales clásticos, desde arcillas y limos hasta conglomerados, con una potente intercalación de elementos volcánicos en la parte media y otras menores en el tramo superior, predominando las rocas psamíticas. Está presente con la Formación El Áspero (complejo volcánico), brechas y tobas de colores claros, verdoso y grisáceo, que afloran en el sector oriental y central del valle y con la Formación El Cajón (Araucanense), que domina en el sector oriental, central y austral del área de estudio, compuesta por un conjunto de elementos clásticos y volcánicos, de color grisáceo.

El Cuaternario incluye materiales de acarreo, que son depósitos arenosos con intercalaciones arcillosas y numerosas camadas conglomerádicas, dispuestas en niveles aterrazados, ubicados en una franja más o menos estrecha al poniente del río El Bolsón. Los aluviones recientes corresponden a depósitos del Holoceno y son en general arenosos; se encuentran en el valle del río El Bolsón, como así también constituyendo los conos aluviales actuales.

El relieve está marcado por la estructura en bloque, debido a los intensos movimientos que tuvieron lugar durante el Cenozoico. Las fracturas son en su mayoría inversas, de rumbo predominantemente meridiano, desplazadas hacia el nornordeste-sudsudoeste y han ladeado los bloques hacia el naciente; son las fallas que constituyen el borde oriental de la Puna.

\section{Geomorfología}

El valle de El Bolsón es un valle angosto, que toma el nombre del curso de agua permanente que lo recorre de Norte a Sud, el río El Bolsón, perteneciente a la cuenca de Belén. El área de estudio alcanza sus mayores cotas en la Sierra de Papachacra, con alturas de $4.450 \mathrm{msnm}$ y Chango Real, con $4.550 \mathrm{msnm}$, ubicadas al oeste y noreste del área de estudio; en tanto hacia el sur, la misma concluye al norte de la localidad de Villa Vil, donde alcanza una altura mínima de $2.200 \mathrm{msnm}$. Estas características le brindan una importante variabilidad ambiental, especialmente considerando que constituye una zona de transición entre dos áreas arqueológicas muy importantes desde el citado punto de vista en el período Formativo: la Puna, por la producción de "ganado de la tierra" y los valles bajos, por la producción agrícola (Aschero y Korstanje, 1996).

Las serranías presentan una variada morfología vinculada a la estructura geológica, la litología y posición topográfica (Figura 3). Las laderas en el basamento cristalino y en metamorfitas evidencian una moderada incisión, en un contexto de predominio relativo de la estabilidad. Por encima de $4.300 \mathrm{msnm}$ se observan los efectos de procesos periglaciares, aparentemente inactivos. Hacia el pie de las mismas y en los afloramientos del valle ubicados en sectores más deprimidos son frecuentes los deslizamientos, algunos de ellos de importantes dimensiones (Fauqué y Tchillinguirian, 2002).

Hacia el este, un escarpe estructural constituye el cierre de la cuenca; el mismo se halla disectado por numerosos cursos de agua cortos y paralelos. En el fondo del valle las sedimentitas terciarias del Grupo El Bolsón se encuentran altamente erosionadas, conformando un paisaje de Badlands.

Los depósitos más recientes se encuentran mayormente en el fondo del valle. Incluyen acarreos fluviales que constituyen terrazas y conos aluviales del Holoceno (sensu lato) y el lecho del río El Bolsón. Asimismo, se observaron depósitos eólicos, los más importantes de los cuales forman acumulaciones en el sector norte de la cuenca, que constituyen un frente de dunas que avanza desde la puna con rumbo WNW-ESE. Los sitios Barranco Don Silvestre y Alto Juan Pablo, ambos asignados al Formativo, están cubiertos parcialmente por dunas; el primero de ellos presenta un fechado de 958 años cal a.d. y el segundo de 1239 años cal a.d. Esta última datación se considera dudosa, dado el contexto arqueológico del sitio. No obstante, ambos casos permiten corroborar que el avance más reciente de las dunas corresponde al último milenio.

\section{Suelos}

En El Bolsón, las características de los factores formadores de los suelos (clima, material parental, biota, relieve y tiempo) dan lugar a suelos de muy escaso desarrollo, con perfiles tipo $\mathrm{A} / \mathrm{C}, \mathrm{A} / \mathrm{C} / 2 \mathrm{C}$, $\mathrm{A} / \mathrm{R}$, dependiendo de la unidad geomorfológica que se considere. En general, presentan texturas gruesas, escasa materia orgánica, colores claros grisáceos o 


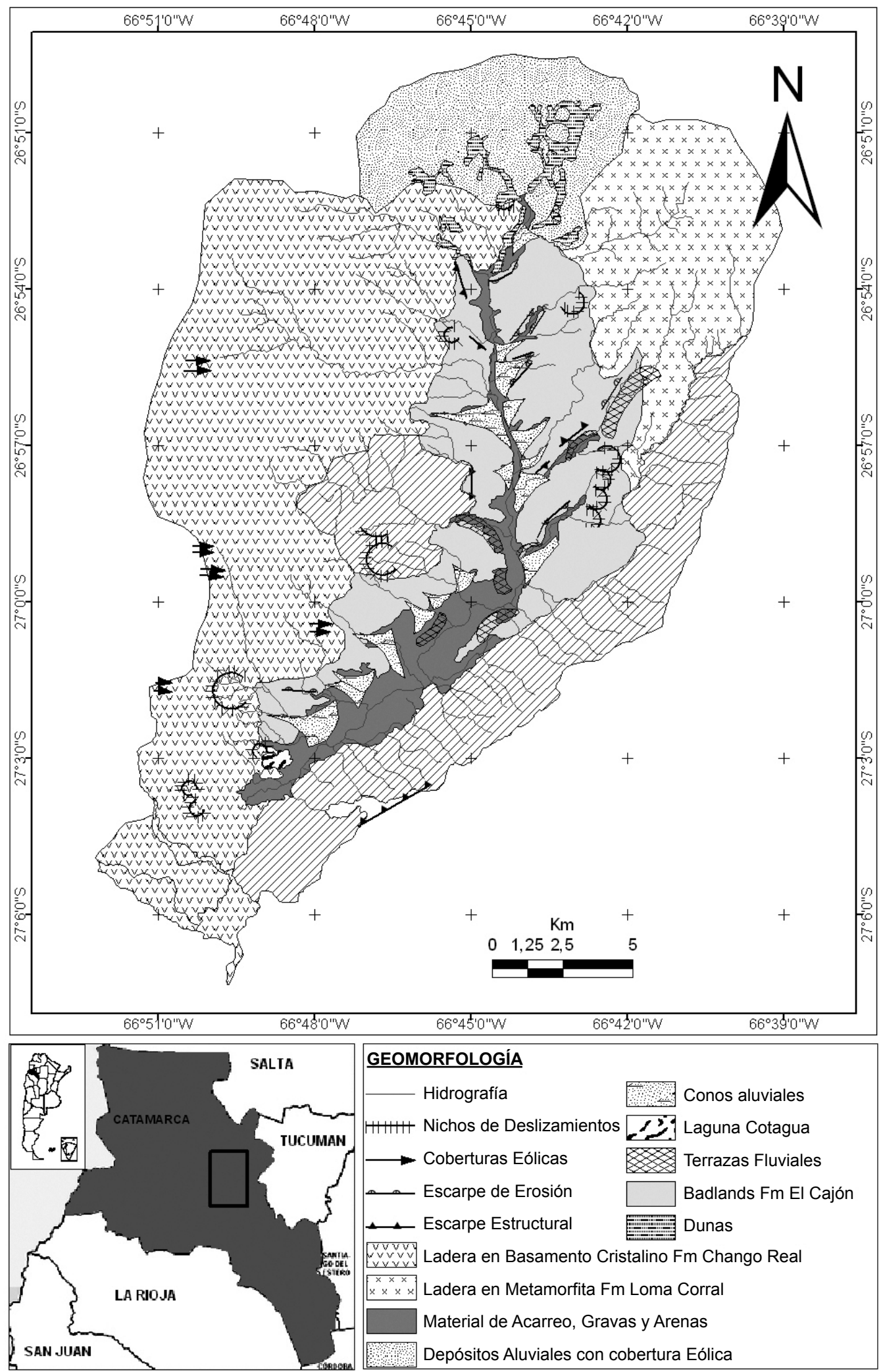

Figura 3. Mapa geomorfológico del área de estudio. 
parduscos y $\mathrm{pH}$ neutros a ligeramente ácidos. En el fondo de valle y en sectores con pendientes bajas a moderadas y que acceden al riego, los suelos permiten un uso agrícola-ganadero "sostenido", lo que significa que, a pesar de su escaso desarrollo pedológico, tienen una fertilidad adecuada tanto para cultivos como para pasturas.

\section{Vegetación}

El Valle de El Bolsón constituye un área transicional o "ecotono" entre los ambientes de valle (1.800 msnm) y Puna (3.400 msnm); corresponde a las provincias fitogeográficas de monte, Prepuna y Puna (Figura 4, Cabrera 1976).

La Provincia del Monte se extiende por el centro de Catamarca aproximadamente a $1.800 \mathrm{msnm}$. Son predominantes las estepas xerófilas y sammófilas, con dominancia de Zigofiláceas del género Larrea sp p., formando el "jarillal" en bolsones, suelos arenosos y pedregosos como comunidades climáxicas. Existen también comunidades serales como los bosques de algarrobo: Prosopis alba, P. nigra, P. flexuosa; en suelos de napas poco profundas y a orillas de ríos de agua permanente son abundantes las Cactáceas, indicando una transición con la Prepuna y la Puna por encima de $3.400 \mathrm{msnm}$.

La Provincia Prepuneña está condicionada no solo por su altura sino también por la orientación de sus quebradas, con suelos de montañas, inmaduros, pedregosos-arenosos, sueltos y muy permeables. Predominan las estepas arbustivas, cardonales, bosquecillos enanos, se relaciona estrechamente con la Provincia del Monte por su fisonomía de estepa o matorral arbustivo, se diferencia en la poca importancia o ausencia del género Larrea, la abundancia de Cactáceas columnares del género Trichocereus y varias especies endémicas.

La Provincia Puneña se extiende entre 3.400 y $4.500 \mathrm{msnm}$, con altiplanicies, cerros y quebradas de suelos inmaduros, muy pobre en materia orgánica, arenosos o pedregosos. Dominan la estepa arbustiva de Fabiana densa (tolilla), Adesmia horridiuscula (añagua), Baccharis boliviensis (chijua), matorrales de tola, estepas de Chenopodiaceas Atriplex spp., estepa de Ephedra spp., etcétera.

\section{Clima}

El clima es templado árido de sierras y bolsones, que se define por los contrastes de temperatura y monto pluvial entre las sierras y los bolsones. Es la resultante en parte del relieve, orientado de norte a sur, que actúa de barrera a los vientos del este y del oeste con la consecuente continentalidad y tendencia a la aridez características de la Provincia de Catamarca (Irurzun, 1978). Las precipitaciones, que se producen principalmente en verano, son escasas y con importantes variaciones interanuales; la media se estima en $175 \mathrm{~mm}$ anuales. Registros pluviométricos en el valle, entre noviembre de 1994 y mayo de 1999 evidencian que las precipitaciones se incrementan con la altura (Korstanje, 2005).

\section{Resultados}

\section{Ocupaciones desde el Formativo a la actualidad}

El valle ha sido ocupado y transformado desde al menos 233 años cal a.d., que es el fechado del sitio arqueológico más temprano con el que contamos (Figura 1, Cueva Pintada). No obstante esto, no descartamos ocupaciones de cazadoresrecolectores holocénicos, que si bien no han sido aún detectadas en la zona, son altamente probables por la alta movilidad de estos grupos y su presencia en la zona colindante de la Puna. De todos modos, hay un hallazgo aislado de una punta de proyectil "cola de pescado" que indicaría un paisaje cazador muy temprano (Korstanje, 2005).

El valle muestra secuencias de ocupación principalmente desde lo que conocemos como Formativo (primeros agricultores, ca. 700 años a.C.-1000 años a.d.) en aleros, cuevas y sitios a cielo abierto. En general, las ocupaciones son dispersas entre campos de cultivo y son pocos los casos en los que se ve concentración residencial, aunque sí agrícola (Quiroga y Korstanje, 2007).

Por otro lado, la estructuración del espacio residencial y agrícola no evidencia cambios dentro del largo lapso del Formativo (Korstanje, 2005), sino recién ya entrados en el Período de Desarrollos Regionales (1000-1400 a.d.), en forma de aldeas y campos de cultivo agrupados, o bien también en sitios con reparo (aleros y cuevas) en los sectores central y meridional (Korstanje, 2005; Quiroga, 2005).

No hay evidencia clara aún de que los inkas hayan establecido asentamientos en la zona, aunque ciertamente el camino que une otros sitios de esta época entre Puna y valles habría pasado por aquí también. Para el período colonia se propone un importante cambio en la producción del valle, orientándose ahora hacia la cría de ganado y pasturas (Quiroga, 2005). 


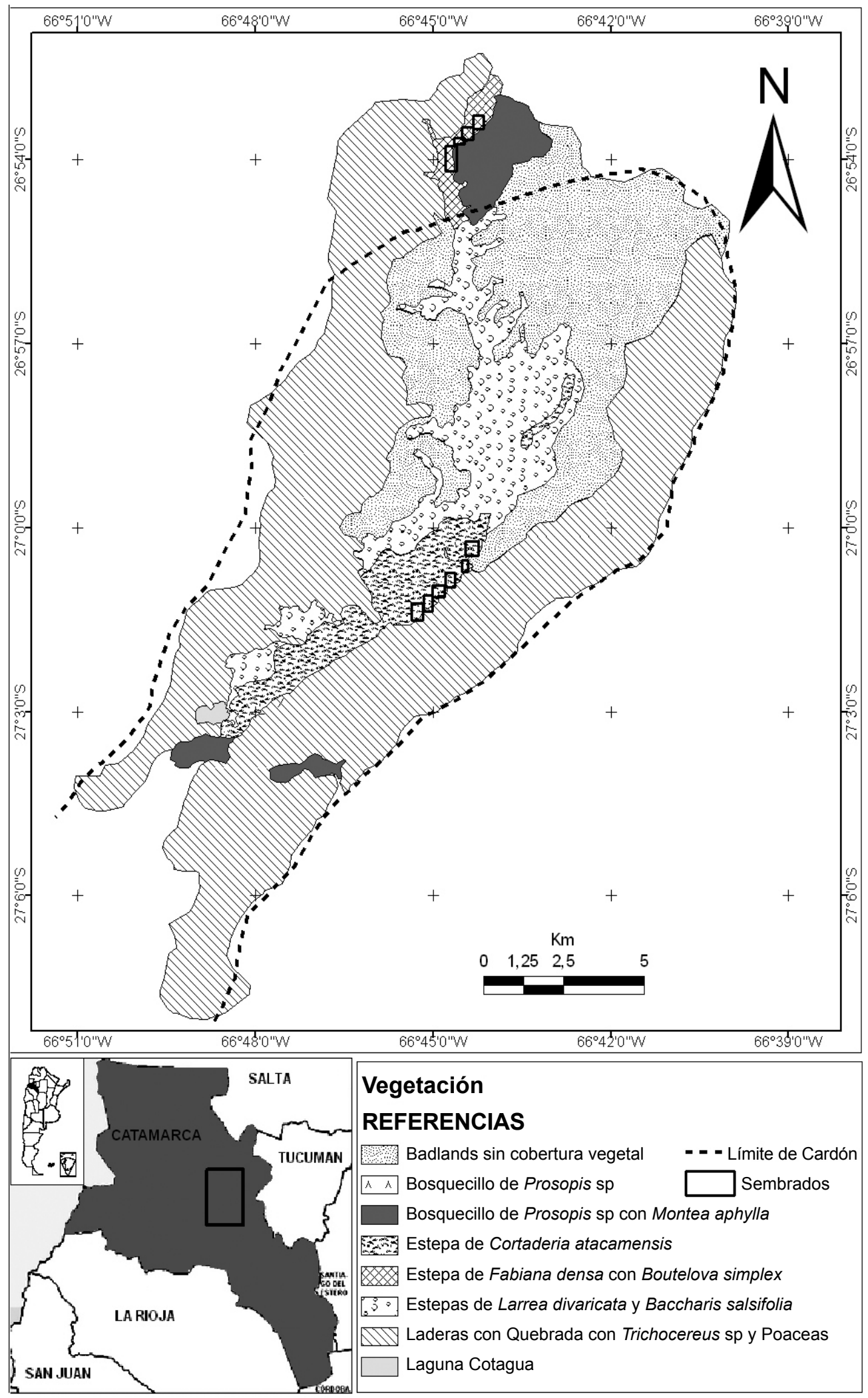

Figura 4. Mapa de vegetación del área de estudio. 
Arqueología: Sitios arqueológicos agrícolas de El Bolsón y áreas vecinas. Los sitios que tomamos en cuenta en este trabajo pertenecen al sector septentrional del valle, que es donde se concentra la mayor cantidad de sitios Formativos agrícolas.

Sitio Morro Relincho: Emplazado entre 3.280 y $3.100 \mathrm{msnm}$, en pendientes mayores a $20 \%$, con vegetación altoandina y colindando con un barranco, que cae varios metros hacia el río en una abrupta pendiente. Se trata de 17 círculos de piedra cuyas dimensiones varían entre 22 y 3,70 m de diámetro, la mayoría de ellos corresponden a estructuras de tipo productivo. El espacio construido tiene un área de 1,3 ha.

Sitio El Alto El Bolsón: Se encuentra emplazado sobre la superficie de un cono aluvial, desarrollado por la depositación cíclica de materiales transportados por flujos de detritos, provenientes de las laderas aledañas. El cono está flanqueado por dos cursos fluviales, que produjeron su disección, alcanzando la mayor profundidad de incisión hacia la parte apical y se encuentra entre 2.950 y $3.200 \mathrm{msnm}$. El sitio completo (sectores tempranos o Formativos y post-Formativos) incluye un total de 327 estructuras dispersas. Hemos podido detectar distintas modalidades productivas que corresponderían a momentos cronológicos bien diferenciados, aunque también se observa en la arquitectura que se reocupan espacios más antiguos. Este trabajo solo toma en consideración la zona apical que presenta rasgos Formativos. En este sector, las estructuras agrícolas de piedra son de distintos tipos: circulares aisladas y agrupadas; alineamientos transversales a la pendiente y aterrazamientos cerrados.

Sitio Alto Juan Pablo: El sitio se localiza sobre una pequeña mesada entre 3.000 y $3.100 \mathrm{msnm}$, a su vez en una elevación aislada y de acentuada pendiente constituida por materiales terciarios cubiertos por derrubios cuaternarios. En la zona oriental de la elevación se observa un sector de médanos depositados sobre un valle de configuración fluvial. Sobre la ladera sur se distingue una vega en retracción, la que constituye un importante recurso para forraje.

El sitio presenta una ocupación Formativa y posiblemente post-Formativa, observable en una sucesión de seis estructuras agrícolas de piedra articuladas sin solución de continuidad, de formas y tamaños variables (aunque ninguna de ellas supera los 50 metros). Estos recintos se hallan interconectados, extendiéndose longitudinalmente en forma escalonada, siguiendo la pendiente general de este a oeste. Desde su detección se observaron características que llamaron la atención, como ser el difícil acceso y aparente aislamiento del emplazamiento agrícola en relación con un área de habitación, como también la ausencia de canales de regadío en un lugar donde actualmente la agricultura a secano es difícil de imaginar.

A partir del análisis de la muraria de las estructuras, podemos plantear una continuidad en las técnicas constructivas de las mismas, ya que no hay ningún elemento que indique una modificación en las decisiones de selección de las rocas para construir los muros o en la construcción de los mismos.

\section{Ejemplos de la interpretación suelos-microfó- siles en los campos agrícolas}

\author{
a) En Morro Relincho (basado en Korstanje y \\ Cuenya, 2008, 2010):
}

Ejemplo de círculo de piedra grande, aislado: Estructura XVI, sondeo en trinchera de $2 \times 0,50 \mathrm{~m}$ en el centro de la estructura. Muestras 20-25 cm; $30-35 \mathrm{~cm}$; $40-45 \mathrm{~cm}, 50-55 \mathrm{~cm}$ y $60-65 \mathrm{~cm}$.

Descripción pedológica particular:

El sedimento es suelto, húmedo y homogéneo, con pequeños clastos. Texturalmente presenta clases similares dentro de las gruesas (arenoso franco) en los niveles superiores volviéndose algo más finos en profundidad (franco arenoso) a partir del nivel 60-65 cm. Los contenidos de materia orgánica tienen los valores esperables para las características de la zona en los niveles superiores; en el nivel 40-45 cm muestra una abrupta disminución a casi la mitad y nuevamente valores que se incrementan en profundidad, al contrario de la curva normal de campo abierto. El pH va de levemente ácido a neutro en profundidad.

\section{Descripción microfósiles}

El nivel 20-25 cm muestra una alta presencia de Pooides, seguidas de Arundinoides y simil Arecaceae sobre un bajo número total de silicofitolitos, donde morfológicamente predominan las Estrobiololitas seguidos de las Microprismatolitas. Hay presencia de Panicoides, aunque en muy baja proporción. El nivel siguiente es muy similar, con un leve incremento 
en la frecuencia total de silicofitolitos y la presencia probable de almidón en forma de ojo de mosca, tipo Chenopodiaceae. En el nivel 40-45 se mantienen las tendencias por formas y tribus, pero se incrementa dramáticamente el número total de especímenes, con lo que también aumenta la frecuencia de Panicoides. En los dos niveles siguientes vuelve a bajar la cantidad total a los valores anteriores, bajando la variabilidad de formas y tribus hasta solo quedar prácticamente Estrobiololitas y Pooides.

Respecto de los otros microfósiles, la muestra es muy variada e interesante. En el nivel de 40-45, que es el de más silicofitolitos, también hay presencia de anillos de celulosa y gránulos de almidón. Los dos niveles posteriores tienen abundantes microcarbones. Es llamativa la presencia de abundante polen en todos los niveles. No hay diatomeas en los dos niveles inferiores, que son los que detectamos como "naturalmente" húmedos durante la excavación.

Se interpreta un incremento de uso del espacio en los niveles 40-45 y 50-55, probablemente con cultivo de maíz, ya que es el nivel donde más frecuencia de Panicoides hay (dato que coincide con las observaciones de test ciego en el microscopio) y quizás, quínoa. Los silicofitolitos de ulluco necesitan de otra evidencia independiente para poder interpretarlos como tales. Es posible que la celulosa esté acompañando este proceso o sea parte de un proceso independiente que todavía no podemos explicar. Estos datos coinciden con la fuerte pérdida de materia orgánica en ese nivel.

b) En El Alto El Bolsón (basado en Korstanje y Cuenya, 2008, 2010):

Ejemplo de terrazas con una sola pared lateral: Estructura 99. Muestras a $0-10 \mathrm{~cm}, 0-20 \mathrm{~cm}$ y $20-30 \mathrm{~cm}$ de profundidad.

El perfil de suelo en esta estructura tiene escasa profundidad $(30-35 \mathrm{~cm})$, debido a que asienta sobre rodados fluviales. El sedimento es suelto y homogéneo, reflejándose en la textura que presenta todo el perfil dentro de las clases texturales gruesas (franco arenoso), y a consecuencia de esto el material está escasamente estructurado. Los contenidos de materia orgánica son moderadamente ricos en el nivel superior, disminuyendo a moderada en los niveles inferiores. El $\mathrm{pH}$ presenta valores neutros en todo el perfil.

Nuevamente hay un aumento importante de silicofitolitos en los niveles más profundos, lo cual es contrario a situaciones no antropizadas. Entre el nivel 0-10 y los dos posteriores hay un cambio interesante en la distribución de las frecuencias de morfotipos. En el primero predominan las Microprismatolitas, seguidas de Estrobiololitas y Globulolitas, mientras que en los dos siguientes el predominio es de Estrobiololitas, seguidas de Microprismatolitas, Globulolitas y Halteriolitas. La frecuencia de Panicoides es casi insignificante en el primer nivel y vuelven a aparecer en mayor concentración en el último nivel. El segundo nivel no tiene Panicoides. La predominancia en los tres niveles es de Pooides y, en menor medida, Arundinoides. En el nivel 0-10 el polen es de Poaceae.

Resulta llamativa la presencia de gran cantidad de almidones medianos en los niveles inferiores. En el nivel 10-20 la proporción de almidones es considerablemente más alta y son de tipo Solanum sp ("papa") y hay presencia de esferulitas y fragmentos de silcofitolitos de Cucurbitáceas.

En el nivel 20-30 disminuye la presencia de almidón, aparecen almidones del tipo "ojo de mosca" (Chenopodiaceae); no hay esferulitas, hay algo de polen de maíz y hay un incremento de microcarbones.

Esta estructura de cultivo, desde el punto de vista de la arquitectura agrícola, muestra las tendencias precedentes de uso del suelo para cultivo, pero con algunos parámetros distintos a los anteriores, que podría estar explicando un manejo diferente, en el sentido de una rotación de cultivos o una práctica agrícola más especializada. Pensamos que en el nivel inferior se cultivó maíz (combinación de Panicoides, microcarbones, polen, silicoalgas) y luego se fertilizó el terreno para cultivar tubérculos. Esto se basa en que en el nivel 10-20 tenemos una alta presencia de almidones, fertilizantes naturales ("guano"), baja cantidad de microcarbones (el rastrojo de tubérculos no se quema), baja frecuencia de silicofitolitos (los tubérculos casi no los producen) y ausencia de silicofitolitos de Panicoides. Los porcentajes de materia orgánica y fósforo que se mantienen altos en los niveles de abajo (quizás por la presencia de abonos) y el aumento de silicofitolitos en los mismos confirman esta práctica agrícola en esta estructura. Por ahora no interpretamos las Cucurbitáceas como cultivo, ya que son muy pocos los microfósiles asignables a este taxón.

Ejemplo de doble círculo o canchones: Estructura 104. Muestras a $5-15 \mathrm{~cm} ; 15-30 \mathrm{~cm}$ y $30-45 \mathrm{~cm}$. 
Los materiales edafizados presentan texturas gruesas a lo largo de todo el perfil (arenoso franco) con escasa estructuración, rasgo propio del tamaño de las partículas que lo constituyen. El perfil se presenta de fresco en los primeros niveles, a húmedo en profundidad. Los contenidos de materia orgánica son buenos hasta $30 \mathrm{~cm}$ de profundidad, decreciendo considerablemente (casi a la mitad) en los últimos centímetros. El pH en todo el perfil es levemente ácido.

En general, las muestras tienen mucha mayor abundancia de silicofitolitos que las que analizáramos más arriba. Respecto de estos, el nivel más interesante es el segundo (15-30), donde hay un considerable aumento de los mismos. Es en este nivel también donde aparecen los Panicoides y se determina un claro contexto maicero en las observaciones de microscopio. También se reportan silicofitolitos encadenados tipo Canna sp. ("achira"), pero no los tomamos como tales hasta no profundizar su estudio, en tanto son escasos y el clima no es apto para tal cultivo. En cuanto a las morfotribus, no hay grandes cambios, manteniéndose la tendencia de predominar las Estrobiololitas, seguidas de Microprismatolitas, Globulolitas y Halteriolitas. Los almidones están en el nivel más superficial, donde también hay comparativamente gran cantidad de anillos de celulosa, polen de gramíneas y microcarbones. La variabilidad de silicoalgas es notable. En el segundo nivel, en cambio, aparecen las esferulitas y desaparecen los microfósiles anteriores, excepto el microcarbón. Mientras que en el tercer nivel solo hay microcarbón (muy abundante otra vez) y esporas, pero se mantienen las características de contexto maicero de acuerdo con los silicofitolitos y la abundancia y variabilidad de silicoalgas. El polen es de Gramíneas. La materia orgánica es igualmente alta en los dos niveles superiores y decrece en el nivel inferior.

Es probable que esta estructura (bien conservada pero de muros muy bajos y cercana a la toma de agua) haya sido utilizada alternativamente como corral y como campo de cultivo, lo que se apoya no solo en las evidencias microfósiles y de niveles de materia orgánica, sino en la arquitectura de la misma. Es posible también que haya habido una ocupación superior más moderna, con otro tipo de cultivo que no hemos podido distinguir. La abundancia absoluta de silicofitolitos es mucho mayor que en el resto de las muestras, excepto los casos de viviendas. El primer nivel aparece posiblemente con alguna actividad de tipo basurero, patio de tareas, etc., mientras que el segundo debe haber sido cultivado con maíz por la alta presencia de Panicoides y presencia de esferulitas. La situación inversa -o sea, un corral en lugar de campo de cultivo y por lo tanto esferulitas implicando "guano" pero no fertilizante y Panicoides como ingesta de los camélidos- no parece probable debido a las proporciones en la abundancia de ambos ítems. El nivel inferior podría corresponder a un nivel de quema inicial antes de cultivar. Entre las diatomeas predominan las Nitzchias y Epitemas y en algunos casos hay Surirellas y Dentículas.

c) En Alto Juan Pablo (basado en Maloberti, 2012):

Ejemplo de canchón de cultivo: Estructura 5. Horizontes pedológicos identificados a campo: A: 0 a $16 \mathrm{~cm}$ y C: 16 a $72 \mathrm{~cm}$. Muestras a 0 a $16 \mathrm{~cm}$; 16 a $30 \mathrm{~cm} ; 30$ a $45 \mathrm{~cm} ; 45$ a $60 \mathrm{~cm}$ y 60 a $72 \mathrm{~cm}$.

El sedimento es suelto y homogéneo, reflejándose en la textura que presenta todo el perfil dentro de las clases texturales gruesas (franco arenoso) y a consecuencia de esto el material aparece escasamente estructurado. Los contenidos de materia orgánica son extremadamente pobres en $\operatorname{los} 30 \mathrm{~cm}$ superiores aumentando levemente en profundidad, al contrario de la curva normal de campo abierto. El $\mathrm{pH}$ va de neutro a levemente ácido en profundidad.

En todos los niveles correspondientes a esta muestra se observó una preponderancia de silicofitolitos de la subfamilia Pooideae, seguidos de los correspondientes a Panicoides y en último término Arundinoides, salvo en el nivel superficial donde se encuentra mayor prevalencia de los silicofitolitos de Arundinoideae sobre los de Panicoideae. La subfamilia Chloridoideae aparece escasamente en algunas de las capas. Las dicotiledóneas son representadas tanto por placas perforadas como así también por fitolitos esféricos faceteados correspondientes a Cucurbitaceae. Estos últimos presentes en todos los niveles salvo en el superficial. Asimismo, a lo largo de toda la secuencia a excepción del nivel superficial se detectaron gránulos de almidón afines a maíz y en los niveles correspondientes a los 15 a $30 \mathrm{~cm}$ y 45 a $60 \mathrm{~cm}$ se hallaron silicofitolitos en cruces diagnósticas de este cultígeno (sensu Pearsall et al., 2004). Por otro lado, en el último nivel mencionado detectamos agrupaciones de almidón tipo "ojo de mosca" afines al conjunto Chenoamarantaceae y también almidones asignables a Solanum sp. Las esporas y los microcarbones corresponden a los microfósiles más numerosos en las muestras, luego de los silicofitolitos. Las diatomeas aparecen en mayor 
cantidad solamente en la muestra correspondiente al nivel superficial, la que constituye a su vez la única en la que no se registraron almidones. Los anillos de celulosa se observaron en la mayoría de las muestras (salvo en la capa correspondiente a la superficie y entre 45 y $60 \mathrm{~cm}$ ). Durante el análisis de estas muestras encontramos un gran número de microfósiles silíceos fragmentados, lo mismo fue observado en algunas esporas. Finalmente, en las muestras subsuperficiales se detectó una disminución de gravillas en las matrices sedimentarias.

Arquitectónicamente la estructura fue interpretada como un canchón de cultivo. Desde los microfósiles proponemos para este caso el probable cultivo continuado en toda la secuencia (a excepción del nivel superficial considerado como un suelo no cultivado por ausencia de microfósiles afines a cultígenos). Se observó una recurrencia en la asociación de cultivos de maíz y Cucurbitaceae. Solo en una de las capas se registró la posible incorporación de papa y de alguna chenoamarantácea. Desde los análisis de materia orgánica vemos que los resultados del total de estas muestras indican una marcada disminución de la misma en comparación con el perfil extrasitio, lo que podría indicar un agotamiento de suelos por actividad agrícola.

Por otro lado, la ausencia de esferulitas entre los conjuntos de microfósiles hace difícil pensar hasta ahora en la aplicación de guano como fertilizante, sin embargo debido al valor elevado de las esporas, hemos pensado la posibilidad de que se esté aplicando algún tipo de abonado vegetal, siendo las esporas el indicador de fenómenos de putrefacción de residuos vegetales. Cabe aclarar que la relación entre esporas y eventos de putrefacción es altamente hipotética y necesita ser corroborada.

Al comparar los conteos de microfósiles de las muestras provenientes de esta calicata con aquellos de la cata extrasitio, vemos, respecto de las diatomeas, un conteo superior en el nivel superficial a los registrados en esta última cata, mientras que en los restantes niveles las mismas aparecían en igual o menor cantidad. Este dato lo consideramos de gran importancia para pensar el tema del riego. Porque los valores obtenidos en las muestras extrasitio son tomadas como indicadores de condiciones no cultivadas (y por ende no bajo riego), los conteos superiores de diatomeas podrían ser tomadas como posible evidencia de riego. Esto no sucedió en ninguna de las muestras con asociación a microfósiles afines a algún cultígeno. Esto nos podría estar indicando la probable ausencia de agricultura bajo riego, lo cual se corresponde con la no identificación de canales en zonas aledañas. En cuanto a los microcarbones, tenemos valores variables que superan, igualan o caen por debajo de las frecuencias de las muestras extrasitio, sin embargo en aquellos casos con bajos valores de materia orgánica, sumada a la abundancia de fitolitos y de microcarbones presentes en numerosas muestras con evidencias positivas de microvestigios afines a taxones cultivados, pueden estar indicando quema de rastrojos.

Por otro lado, hemos encontrado en todas las muestras con evidencia de microvestigios asociables a cultívenos, anillos de celulosa, salvo en el nivel que presenta almidones de Solanum sp. y de Chenoamarantaceae. Los anillos de celulosa son presentados por Korstanje y Cuenya (2008, 2010) como posiblemente producidos por la ingesta animal de tallos no completamente digeridos, siendo frecuentes de encontrar en las heces de los camélidos, por lo que son comúnmente hallados en el guano. En este punto tenemos nuevamente la imposibilidad de explicar la presencia de estos anillos en relación con la fertilización con guano, ya que, como anteriormente mencionáramos, no se registraron esferulitas en ninguna de las muestras.

La disminución de gravillas en las capas subsuperficiales podría explicarse por los despedres propios a la preparación de los suelos previos a la siembra, mientras que el gran número de microfósiles fragmentados puede atribuirse al laboreo de los campos agrícolas.

\section{Secuencias sedimentarias del Holoceno}

Las investigaciones sobre depósitos del Holoceno en la cuenca del río El Bolsón tienen en el testigo de la laguna Cotagua la secuencia más antigua conocida hasta el presente. La columna se obtuvo en el lecho seco de la laguna mencionada y tiene una profundidad de $9 \mathrm{~m}$. Fue objeto de diversos fechados que le asignan una edad Holoceno Medio y Superior (4415 años cal a.C. a $870 \mathrm{~cm}, 610$ años cal a.d. a $590 \mathrm{~cm}$ y 1546 años cal a.d. a $17 \mathrm{~cm}$ de profundidad); se destaca un incremento de hasta 10 veces en la tasa de acumulación a partir del Formativo (610 años cal a.d.). Los sedimentos son de texturas arenosas, con intercalaciones limoarcillosas, en parte con abundante materia orgánica. Se destaca, de base a techo, la tendencia a la reducción 
de los estratos de arena gruesa y el aumento de la presencia de arenas medias y finas; esto se interpreta como un progresivo reemplazo de los materiales de laderas (arena gruesa) por los materiales eólicos, con retransporte fluvial (con más de $80 \%$ de arena media y fina).

Las terrazas fluviales del río El Bolsón se reconocen principalmente por debajo de $2.300 \mathrm{msnm}$ y por sobre $2.900 \mathrm{msnm}$, en tanto entre ambas cotas, en el sector central del área de estudio, predominó la agradación, por lo que no hubo un desarrollo relevante de las terrazas. Al norte de Villa Vil se encuentra un único nivel de terraza de $12 \mathrm{~m}$, compuesto por arenas medias y finas, en parte limosas, con algunos lentes de grava y niveles ricos en materia orgánica, con restos de plantas y pedotubos. En esta terraza se hallaron restos atribuidos a basureros arqueológicos (cerámica, huesos, carbón); obteniéndose fechados de 931 y 1214 años cal a.d. a profundidades de 3 y $5 \mathrm{~m}$ por debajo del techo de la terraza. En las inmediaciones de Los Nacimientos de San Antonio ("La Lagunita"), la terraza tiene $8 \mathrm{~m}$ de potencia y se compone de niveles de flujos de detritos, entre los que se intercalan estratos arenosos, en parte humosos. En ellos también se hallaron restos de un basurero arqueológico, a $4 \mathrm{~m}$ por debajo del techo de la secuencia, datados en 634 años cal a.d. Ambas secuencias permiten asignar la acumulación de los materiales de las terrazas al Holoceno Superior y que el proceso de incisión que les da origen y continúa hasta la actualidad, es posterior a 1300 años cal a.d.

\section{Secuencia polínica de laguna Cotagua (Figura 5)}

Zonación y descripción del diagrama polínico: se pueden observar dos zonas, la primera de las cuales (Zona I) se divide en 3 subzonas.

\section{Zona I}

Subzona IA (4000 años a.C. a 750 años a.C.): corresponde a la profundidad $800-675 \mathrm{~cm}, 10$ s sedimentos son arena gruesa, intercalaciones de arena media a fina y limos arcillosos humosos. Los elementos de la vegetación regional están escasamente representados, destacándose un pastizal puneño rico en Poaceae (25\%), acompañado por estepa arbustiva de Asteraceae. Se observan indicadores de humedad local como Juncaceae (5\%), Cyperaceae $(10 \%)$ y Esporas monolete (con un pico de $25 \%$ ), con valores máximos de porcentajes en esta subzona, lo que indica a este momento como de mayor humedad local a lo largo de la secuencia; los indicadores de disturbio antrópico presentan bajos porcentajes, igual que los elementos de bosque.

Subzona IB (750 años a.C. a 500 años a.d.) se carazcteriza por un aumento de elementos de Puna-Prepuna-Monte como Ephedra sp. (10\%) y Tipo Acacia (5\%), predominando Poaceae con $50 \%$, que disminuye al final de este período. Paralelamente se observan máximos porcentajes de indicadores de disturbio antrópico (Chenopodiaceae/ Amaranthaceae y Malvaceae) y presencia de partículas de carbón vegetal, sugiriendo presión por pastoreo y práctica de quema de pastizales. A escala regional puede observarse un pastizal puneño y el aporte de elementos del bosque como Alnus acuminata (5\%), Celtis sp. (10\%) y Espora monolete (5\%), que se interpreta como incremento de la humedad regional; a pesar de ello se observa la ausencia de indicadores de humedad local (Cyperaceae y Juncaceae).

Subzona IC (610 años a.d. a 1275 años a.d.): los sedimentos son limo, arena gruesa y arena media. Presenta un incremento en los elementos de Puna-Prepuna-Monte (Ephedra sp., Tipo Acacia), indicadores de humedad local y disturbio antrópico (Gomphrena sp., Chenopodiaceae/Amaranthaceae, Malvaceae). Este momento se caracteriza por antropización (pastoreo) y humedad local creciente.

\section{Zona II}

Correspondiente a 1275 d.C.-actualidad, los sedimentos son limos intercalados con arena media y arena gruesa, limos arcillosos. Esta zona presenta elementos de Puna-Prepuna-Monte y Monte (Larrea divaricata, Cercidium praecox), acompañado por un incremento en los indicadores de disturbio antrópico. Una situación inversa ocurre con los indicadores de humedad local (Cyperaceae, Juncaceae, Ranunculaceae, espora monolete y en menor porcentaje de espora trilete), indicando un período de humedad decreciente, hacia las condiciones actuales de semiaridez.

\section{Secuencia de micromamíferos de Cueva de Las Máscaras}

Las asociaciones fósiles de micromamíferos son una herramienta de gran importancia en el estudio 


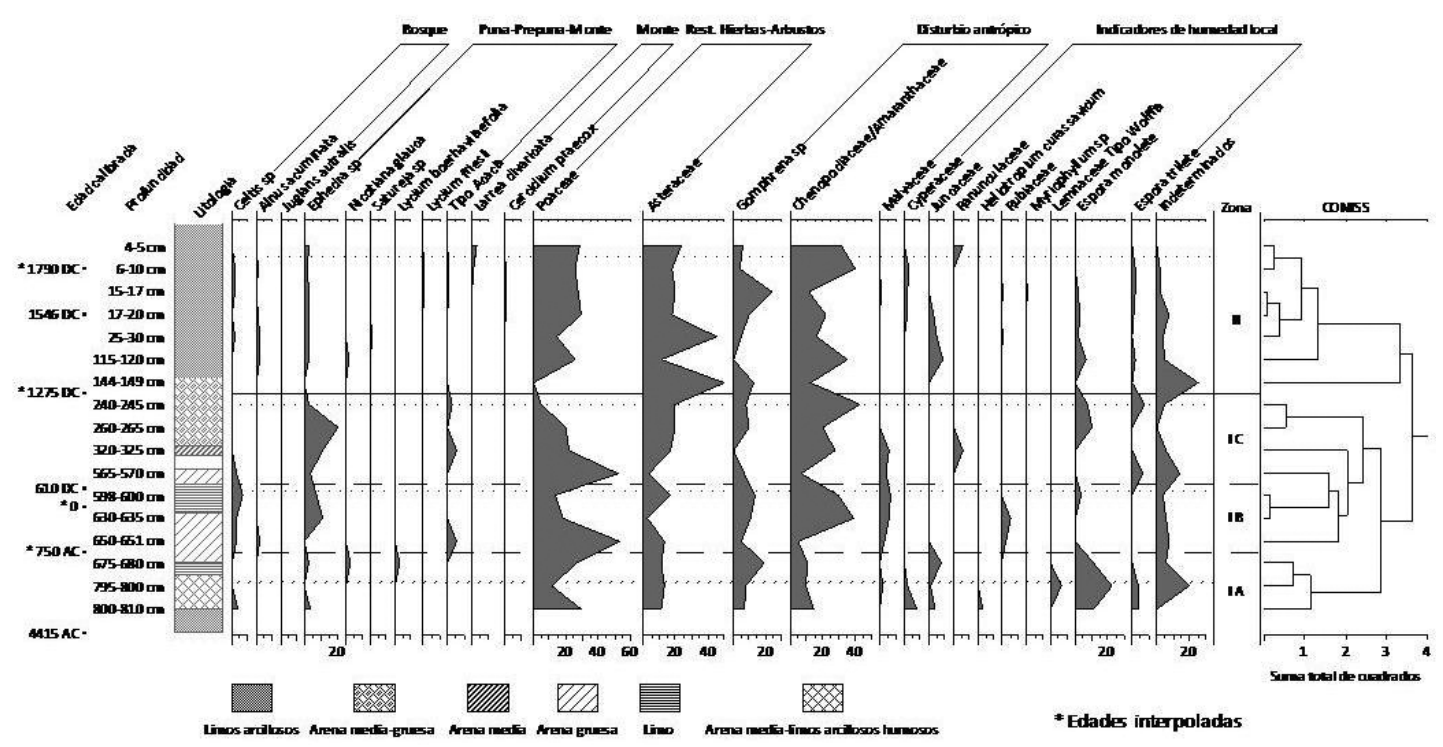

Figura 5. Diagrama polínico de la secuencia de Laguna Cotagua.

de paleoclimas, ya que permiten inferir características ambientales y de vegetación en el momento de formación de los yacimientos (Andrews, 1990). A partir de principios actuales es posible realizar una reconstrucción paleoambiental confiable, ya que los micromamíferos presentan requerimientos ecológicos acotados y la mayor parte del registro está representado por formas vivientes (Tonni y Fildago, 1978). En el Valle de El Bolsón, en el sitio Cueva de Las Máscaras, se estudió el mayor depósito estratificado de micromamíferos del noroeste argentino (Gráfico 1), compuesto por más de 10.000 restos craneales y postcraneales (Ortiz y Pardiñas, 2001; Ortiz y Jayat, 2007; Ortiz, et al., 2012). El material fue excavado en una superficie de $1,5 \mathrm{~m}^{2}$; la secuencia fue dividida en 7 capas definidas artificialmente cada $15 \mathrm{~cm}$ de profundidad, en la que se considera nivel 7 al más profundo y nivel 1 el más superficial y que representa la composición actual de la comunidad de micromamíferos. La edad de la muestra fue establecida en las capas 7 y 5 por dataciones ${ }^{14}$ C AMS: 133 años cal a.d. y 1074 años cal a.d., correspondientemente. Las capas 4, 3 y 2 fueron datadas por ${ }^{14} \mathrm{C}$ : 1161; 1173 y 1293 años cal a.d., respectivamente. La evidencia de ligeras señales de corrosión en los huesos y dientes y la presencia de algunas egagrópilas indica que la secuencia de la Cueva de Las Máscaras se ha generado por la actividad trófica de lechuzas. Estas aves son generalistas en su dieta y presentan zonas de caza relativamente pequeñas, a no más de $5 \mathrm{~km}$ desde el lugar de descanso (Andrews, 1990). Esto asegura un muestreo adecuado de la comunidad de micromamíferos local, por lo que la Cueva de Las Máscaras puede considerarse representativa de los ambientes presentes en el área de estudio en un rango de 2.400-2.800 msnm.

Basándose en frecuencias relativas y a la diversidad de las especies de la secuencia, se reconoce una relativa estabilidad del medio ambiente. Sin embargo, a partir de cambios menores de varias especies se indican fluctuaciones a pequeña escala. Entre las capas 5 y 2 se registra un descenso en la frecuencia de Eligmodontia, especie endémica de ambientes áridos (Mares et al., 2008). Un patrón simultáneo pero opuesto se observa en especies asociadas a pastizales (Calomys musculinus, Oligoryzomys cf. O. flavescens, Akodon spegazzinii, Andinomys edax y Thylamys cf. T. pallidior, Jayat et al., 2008, 2009, 2010). Basados en la frecuencia de estas especies, se infiere que se establecieron condiciones más húmedas probablemente alrededor de 900 a 1200 a.d., coincidente con el Período Óptimo Climático Medieval, el cual, basado en estudios de distintos datos proxies (Alcalde y Kulemeyer, 1999; Carignano, 1999; Cioccale, 1999), fue descrito como un período cálido y húmedo, aproximadamente entre el 1200 y 700 años a.p. en el noroeste argentino. En la capa 2 las frecuencias de las especies indicadoras de condiciones de mayor 


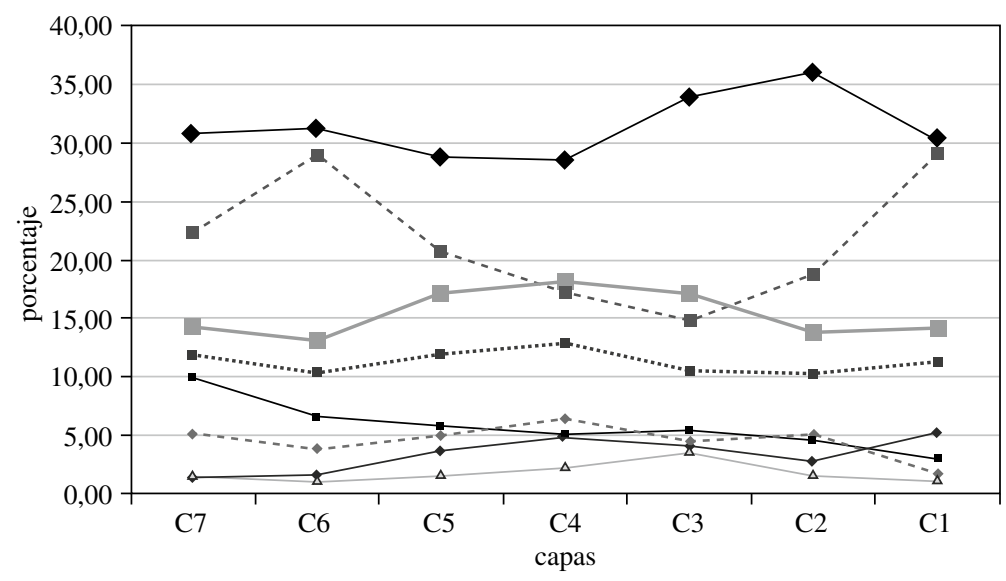

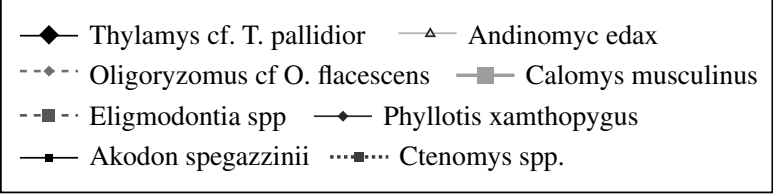

Gráfico 1. Especies dominantes y de mayor abundancia relativa (\%NMI) presente en la secuencia de la Cueva de Las Máscaras.

humedad decrecen simultáneamente con un ascenso de la frecuencia de especies de Eligmodontia sp. lo que indicaría una recuperación de condiciones más áridas, congruentes con la "Pequeña edad de Hielo", 500-150 años a.P. Las frecuencias registradas en la capa 1 son coincidentes con la capa 6 , lo que permite inferir que las condiciones ambientales durante el intervalo alrededor de 1600-1300 años a.P. fueron similares a las que se registran actualmente en el área. En el intervalo de tiempo (1800-1000 años a.P.) la tasa de acumulación de sedimento es mucho menor que en el intervalo 1000-700 años a.P. $(30 \mathrm{~cm}$ de sedimento en aproximadamente 800 años contra $60 \mathrm{~cm}$ en aproximadamente 300 años). La menor acumulación de sedimentos del primer milenio es coincidente con el período donde se registra la menor diversidad, la riqueza de especies más baja y el menor MNI toda la secuencia (capa 6; Madozzo Jaén, 2009).

Estas fluctuaciones climáticas en el Holoceno tardío habrían causado cambios en el ambiente, lo que modificó la extensión de las diferentes unidades de vegetación, reflejándose en las frecuencias de los micromamíferos de cada nivel de la secuencia (Ortiz, et al., 2012). La pequeña zona de caza de las lechuzas no incluye tierras potencialmente útiles para la agricultura, lo que nos permite interpretar nuestros resultados solo a escala local, minimizando la influencia humana en la composición del conjunto.

\section{Interpretación}

Los registros paleoclimáticos más antiguos con los que contamos actualmente corresponden a la parte inferior del testigo de Laguna Cotagua. En él se evidencia una fase algo más húmeda que la actual, que habría comenzado por lo menos hacia los 4000 años a.C. y finaliza hace 750 años a.C. No se han detectado aún hallazgos arqueológicos que puedan ser atribuidos con precisión a este momento.

Posteriormente, entre 750 años a.C. y 500 años a.d., el polen indica el mayor momento de humedad, con antropización creciente e indicios de quema hacia el final del período. A este momento corresponden los primeros sitios formativos. Son sitios residenciales, con variedad de cultígenos en uso (maíz, papa, zapallo, quinoa, amaranto, poroto) y el consumo/aprovechamiento de la fauna autóctona: camélido, taruca, flamenco y quirquincho. Los sitios productivos no presentan evidencia de riego en este momento, pero sí presentan elaborados recursos en la práctica del uso del suelo (Korstanje y Cuenya, 2008). En transición a la siguiente fase, los registros de micromamíferos en la Cueva de Las Máscaras muestran condiciones similares a las actuales.

El valle muestra secuencias de ocupación principalmente desde lo que conocemos como Formativo (primeros agricultores, localmente ca. 400 a.C.-1000 a.d.) en aleros, cuevas y sitios a cielo 
abierto, principalmente en el sector septentrional, que es donde también hay mayor concentración de campos de cultivo de este momento. En general las ocupaciones son dispersas, entre campos agrícolas, y son muy pocos los casos en donde se ve concentración residencial, aunque sí productiva. Por otro lado, la estructuración del espacio agrícola no evidencia importantes cambios en el Valle de El Bolsón dentro del largo lapso del Formativo. A este momento corresponderían los sitios agrícolas de la cabecera de cuenca, sin evidencias de riego (ca. $3.000 \mathrm{msnm}$ ): a) Morro Relincho, en el que se identificó el cultivo de maíz y quinoa, b) El Alto El Bolsón (cuya ocupación continúa en períodos más recientes), en el lugar se cultivó maíz y papa, con uso de guano como fertilizante; algunas estructuras también fueron utilizadas como corrales, c) Alto Juan Pablo, con una asociación de maíz y cucurbitáceas, con la posible incorporación de papa y de alguna chenoamarantácea. Solo en El Alto El Bolsón hay evidencias de fertilización con guano animal y en general en los perfiles hay una marcada disminución de la materia orgánica del suelo cultivado respecto de un perfil extrasitio, lo que podría indicar un agotamiento de suelos por actividad agrícola.

Entre 500 y 1275 años a.d. hay un incremento progresivo en los indicadores de humedad local y, simultáneamente de los indicadores de disturbio antrópico y la estepa arbustiva, en tanto decrece la estepa herbácea. Este lapso se interpreta como de aridez con disminución de las temperaturas. Es el momento en que algunos campos de cultivo empiezan a mostrar claras y duraderas estructuras de riego de tipo canales y represas. Los micromamíferos evidencian contradictoriamente condiciones ligeramente más húmedas. Corresponde también a este momento la principal acumulación del depósito de terraza de Villa Vil y Lagunita, compuestas de sedimentos finos y con evidencias de ocupaciones agroalfareras del Formativo y Desarrollos Regionales interestratificadas. Es probable que estos materiales se hayan acumulado bajo condiciones de escurrimiento reducido, en cauces vegetados y con el aporte progresivo de materiales coluviales y aluviales, producto de la erosión de las vertientes. Coincidentemente, el incremento de 10 veces en la tasa de acumulación observada en la Laguna Cotagua alrededor de 600 a.d., evidencia la inestabilidad de laderas. El final de esta etapa y el inicio de la siguiente, conocida como Desarrollos Regionales
(1000-1400 a.d.), se caracteriza por asentamientos en forma de aldeas y campos de cultivos agrupados en los sectores central y meridional del valle.

A partir de los 1275 años a.d., el registro polínico de la Laguna Cotagua muestra condiciones de humedad decreciente hacia las condiciones actuales de semiaridez e incremento del disturbio antrópico. El registro de micromamíferos, en cambio, ha permitido caracterizar a este momento como de mayor aridez, con mejoras hacia el final del período. Esta etapa final del desarrollo del paisaje presenta dos cambios muy importantes en la dinámica geomorfológica. Por un lado, el sector norte del valle es invadido por dunas provenientes del área de Laguna Blanca, en la Puna, sepultando arroyos de los sectores de cabeceras e incluso cubriendo (por lo menos parcialmente) algunos sitios arqueológicos, como Barranco Don Silvestre y Alto Juan Pablo. Si bien aún no tenemos mayores precisiones respecto de la cronología de este avance, podemos afirmar que el mismo tuvo su apogeo en este momento. Por otra parte, hacia 1300-1400 años a.d., culmina la acumulación de los sedimentos finos en los valles de la alta y baja cuenca, comenzando un ciclo de incisión marcada, que continúa hasta la actualidad. Se interpreta que, en general, continúa el proceso de erosión de vertientes, aunque las mismas ya han perdido los materiales finos superficiales, por lo que se reduce la infiltración y aumenta el escurrimiento superficial, provocando la incisión en los sectores inferior y alto de la cuenca de El Bolsón; el sector medio o central, que es donde se encuentran Laguna Cotagua y Barranca Larga, se encuentra en una situación de depresión geológica que le permite estar al margen de dicho proceso.

\section{Discusión y conclusiones}

La aplicación de distintos proxys para el estudio de la historia ambiental en contextos arqueológicos agrícolas del Valle de El Bolsón, combinados con la información arqueológica disponible, ha permitido contextualizar y valorar los distintos enfoques aplicados, así como también definir las principales tendencias.

El Holoceno Medio, de acuerdo con las evidencias de Laguna Cotagua, se caracterizó por una humedad efectiva algo mayor que la presente, en coincidencia con lo observado en el Valle de Chaschuil (Brunotte et al., 1988; Garleff et al., 1993). La falta de hallazgos arqueológicos que puedan asignarse 
con certeza a este momento, se vincularía en parte por los fuertes procesos que habrían afectado a las laderas de las serranías, especialmente allí donde se encuentran los afloramientos terciarios, así como también a la consiguiente acumulación de sedimentos en el fondo del valle.

La primera parte del Holoceno Superior (entre 750 años a.C. y 500 años a.d.) presenta condiciones climáticas relativamente húmedas. En este marco se dan las primeras ocupaciones del Formativo, inicialmente en aleros rocosos y ya hacia 200 años cal a.d. se cuenta con los que hasta el momento son los sitios agrícolas más antiguos conocidos en El Bolsón. Las condiciones del ambiente fueron seguramente más favorables que las actuales, debido a que estos asentamientos contaron con un ambiente poco impactado y relativamente estable, como se evidencia en la tasa de sedimentación relativamente baja en Laguna Cotagua. En sitios residenciales con campos agrícolas se reconocieron variados cultígenos como el maíz, papa, zapallo, quinoa y amaranto, sin evidencias de riego, pero en algunos casos con aplicación de guano como fertilizante, la ganadería de camélidos y prácticas de quema y rotación de cultivos. A lo largo de este lapso, la antropización del paisaje fue en crecimiento, lo que permitiría inferir un mayor dominio del mismo. Es probable que la mayor disponibilidad de humedad efectiva en la altura, debida a mayores precipitaciones y menor evapotranspiración, haya sido uno de los factores que favorecieron un mayor desarrollo durante el Formativo en el sector septentrional de la cuenca. Brunotte et al., 1988, interpretan que en el valle de Abaucán, los seis primeros siglos de la era, estuvieron caracterizados por una aridez creciente, y se inicia un proceso de acumulación de coluvies en los fondos de valle, originados probablemente por el impacto de las actividades antrópicas bajo las condiciones de mayor aridez.

A partir de 500 y hasta 1275 años cal a.d., el incremento de aridez es reflejado por los indicadores polínicos, en tanto los micromamíferos reflejan el aumento de la humedad local, acompañado por un incremento de temperatura. Los sedimentos de terraza reflejan condiciones de escurrimiento reducido, en cauces vegetados (humedales) y con el aporte progresivo de materiales coluviales y aluviales, producto de la erosión de las vertientes; aparecen evidencias de antropización creciente, y alrededor de 600 a.d. se evidencia la erosión de laderas. El final de esta etapa y el inicio de la siguiente, Desarrollos Regionales (1000-1400 años a.d.), se caracteriza por asentamientos en forma de aldeas y campos de cultivos agrupados. Siguiendo las inferencias de Brunotte et al. (1988) en el Valle de Abaucán, es probable considerar que esta nueva organización se vincule al aprovechamiento de los suelos coluviales acumulados previamente en los sectores más bajos del valle, ya que estos suelos retransportados presentaban las condiciones favorables para el desarrollo agrícola, en las que los niveles de humedad fueron mejores. Otro factor ambiental relevante fue sin dudas el inicio del avance de las dunas desde la Puna hacia los valles del sector septentrional de la cuenca de El Bolsón. Los bruscos cambios morfodinámicos pueden responder a cambios del uso de la tierra, como lo destacan Gale y Haworth (2005), quienes, estudiando los efectos de la ganadería en los momentos de contacto con la migración europea a partir de 1830 en Nueva Gales del Sur, Australia, observan cambios bruscos en la tasa de acumulación del lago Little Llangothlin, que aumenta inicialmente 50 veces producto de la erosión de las vertientes para luego reducirse progresivamente. Este mecanismo se explica, de modo similar a lo que ocurre en la cuenca de El Bolsón, por la existencia en superficie de materiales superficiales más fácilmente erodables que dan lugar rápidamente a importantes transferencias de sedimentos y que luego, al encontrar sustratos más compactos, se reduce o cambia la naturaleza de los procesos; como por ejemplo la aparición de procesos de incisión en los valles.

A partir de 1275 años a.d. los registros palinológicos muestran condiciones de humedad decreciente hacia las actuales condiciones de aridez e incremento del disturbio antrópico. Por el contrario, el registro de micromamíferos de Cueva de Las Máscaras caracteriza este momento como de mayor aridez, con mejoras hacia el final de este momento. Para el período colonial se produce un importante cambio en la producción del valle, orientándose ahora hacia la ganadería (Quiroga, 2007).

La reciente invasión de dunas provenientes de la Puna en el sector norte del valle solo puede ser explicada por una combinación de factores (climáticos, eventos volcánicos con producción de abundante material piroclástico y/o antrópicos) que deberán ser analizados en contextos regionales. En todos los casos, los efectos sobre la cobertura vegetal y especialmente sobre los ambientes de valle 
en el sector norte del valle, habrían sido graves, reduciendo notablemente la productividad. Por otra parte, los procesos de incisión documentados en El Bolsón tuvieron un efecto negativo, al afectar a los humedales con la erosión de los mismos, la aparición de la torrencialidad y disminución de la capacidad de reserva de agua de los mismos.

Por todo lo que antecede, consideramos que el cruce de estas líneas de evidencia ha sido un importante aporte al conocimiento de los paisajes holocénicos y agrarios prehispánicos y que los desafíos que estos resultados iniciales nos presentan serán tenidos en cuenta tanto para el redimensionamiento de nuestras preguntas como para afinar metodologías.

\section{Agradecimientos}

Debido a que se trata de un artículo que sintetiza el trabajo de muchos años, agradecemos a CONICET, ANCyPT y CIUNT por los diversos subsidios recibidos, a quienes colaboraron con nosotros en los viajes de campo y a toda la población del valle de El Bolsón que con tanto cariño nos espera cada año.

\section{Referencias Citadas}

Alcalde, J. y J. Kulemeyer

1999 Holocene in the south-eastern of the Jujuy province, Northwest Argentina, Quaternary International No $57-58$ : 113-116, Reino Unido - Estados Unidos.

Andrews, $\mathrm{P}$.

1990 Owls, Caves and Fossils, Predation, Preservation, and Accumulation of Small Mammal Bones in Caves, with an Analysis of the Pleistocene Cave Faunas from WestburySub-Mendip, Somerset, UK, University of Chicago Press, Chicago.

Aschero, C.A. y M.A. Korstanje

1996 Sobre figuraciones humanas, producción y símbolos. Aspectos del Arte Rupestre del Noroeste argentino, Volumen del XXV Aniversario del Museo Arqueológico "Dr. Eduardo Casanova": 13-31, Instituto Interdisciplinario Tilcara (UBA), Jujuy.

Brunotte, E.; K. Garleff \& H. Stingl

1988 Anthropogene Beeinflussung der Morphodynamik im Bolsón von Fiambalá / Nordwestargentinien. Abh. Akad. Wiss. Göttingen, Math.-Phys. K1., III/41: 307-327. Göttingen, Alemania.

Cabrera, A.L.

1976 Territorios fitogeográficos de la República Argentina. Enciclopedia Argentina de Agricultura y Jardinería, № 2, pág. 1-85.Argentina.

Carignano, $\mathrm{C}$.

1999 Late Pleistocene to recent climate change in Cordoba province, Argentina: geomorphological evidence, Quaternary Internacional $N^{\circ}$ 57-58: 117-134. Reino Unido - Estados Unidos.

Cioccale, $\mathrm{M}$.

1999 Climatic fluctuations in the Central Region of Argentina in the last 1000 years, Quaternary International $N^{\circ}$ 62: 35-47. Reino Unido.

Cruz, A.; L.C. Lupo y J.J. Kulemeyer

2011 Los cambios del paisaje a través de la vegetación en el valle del Bolsón (Belén, provincia de Catamarca). XXXIII Jornadas Argentinas de Botánica, Posadas, Misiones.

Fauqué, L. y P. Tchilinguirian

2002 Villavil rockslides, Catamarca Province, Argentina. Geological Society of America. Reviews in Engineering Geology, XV: 303-324.
Gale, S y R.J. Haworth

2005 Catchment-wide soil loss from pre-agricultural times to the present: transport- and supply-limitation of erosion, Geomorphology No $68: 314-333$, Estados Unidos.

Garleff, K.; H. Stingl y H. Veit

1993 New dates on the Late Quaternary history of landscape and climate in the Bolsón of Fiambalá/Argentina (Province Catamarca). Zbl. Geol. Paläont. Teil I (1/2): 333-341. Stuttgart, Alemania.

Irurzun, J.

1978 Construcción al conocimiento del clima de la provincia de Catamarca. Geografia de Catamarca. Sociedad Argentina de Estudios Geográficos. Serie Especial No 5: 43-81. Buenos Aries, Argentina.

Jayat, J.P.; P.E. Ortiz y M.D. Miotti

2008 Distribución de roedores sigmodontinos (Rodentia: Cricetidae) en pastizales de neblina de Argentina, Acta Zoológica Mexicana No 24 (3), 137-178, México.

Jayat, J.P.; P.E. Ortiz; U.F.J. Pardiñas; G. D’ Elía y J. Salazar-Bravo 2010 The boliviensis group of Akodon (Rodentia: Cricetidae) in Northwestern Argentina: species limits, distribution and the description of a new species, Zootaxa $\mathrm{N}^{\circ}$ 2409: 1-61, Canadá.

Jayat, J.P.; S.E. Pacheco y P.E. Ortiz

2009 A predictive distribution model for Andinomys edax (Rodentia: Cricetidae) in Argentina, Mastozoología Neotropical 16(2), 321-332, Argentina.

Korstanje, M.A.

2005 La Organización del Trabajo en torno a la Producción de Alimentos en Sociedades Formativas (provincia de Catamarca, República Argentina), Tesis Doctoral en Arqueología, Instituto de Arqueología y Museo, Facultad de Ciencias Naturales e I.M.L. U.N.T., Tucumán, Argentina.

Korstanje, M.A

2011 Agricultural crisis in the ancient Southern Andes: Trajectories and Evidence for its Archaeological Study, Archaeology and Economic Crises, Archaeological Review from Cambridge 26 (1): 23-36.

Korstanje M.A. y P. Cuenya

2008 Arqueología de la Agricultura: suelos y microfósiles en campos de cultivo del valle del Bolsón, Catamarca, Argentina. En: Matices Interdisciplinarios en Estudios 
Fitolíticos y de otros Microfósiles (A. Korstanje y P. Babot Eds.) BAR International Series 1870: 133-147.

Korstanje, M.A. y P. Cuenya

2010 Ancient agriculture and domestic activities in north western Argentina: a contextual approach studying silicaphytoliths and other microfossils in soils, Journal of Environmental Archaeology, No 15,(1): 43-63.

Korstanje, M.A.; P. Cuenya y V. Williams

2010 Taming the control of chronology in ancient agricultural structures. Non traditional data sets, Journal of Archaeological Science. 37: 343-349. Reino Unido.

Kulemeyer, J.J.

2005 Holozane Landschaftsentwicklung im Einzugsgebiet des Rio Yavi (Jujuy/Argentina). Dissertation zur Erlangung des Doktorgrades (Fakultat fur Biologie, Chemie und geowissenschaften der Universitat Bayreuth. http://opus. ub.uni-bayreuth.de/volltexte/2005/158/

Madozzo Jaén, M.C.

2009 Micromamíferos del Holoceno tardío de Catamarca: taxonomía, tafonomía y reconstrucción paleoambiental, Tesis de Licenciatura en Ciencias Biológicas, Facultad de Ciencias. Naturales e IML. Universidad Nacional de Tucumán, San Miguel de Tucumán, Argentina.

2010 Micromamíferos del Holoceno tardío de Catamarca: taxonomía, tafonomía y reconstrucción paleoambiental, Mastozoología Neotropical, No 17(1): 229-230, Mendoza, Argentina

Maloberti, M.

2012 El Paisaje Campesino Visto desde Emplazamientos Agrícolas Particulares: Alto Juan Pablo (Departamento Belén, Catamarca), Tesis de grado inédita de Arqueología, Facultad de Ciencias Naturales e IML, Universidad Nacional de Tucumán, Argentina.

Mares, M.A.; J.K. Braun; B. Coyner y R.A. Van den Bussche 2008 Phylogenetic and biogeographic relationships of gerbil mice Eligmodontia (Rodentia, Cricetidae) in South America, with a description of a new species, Zootaxa, $N^{\circ} 1753$ : 1-33, Nueva Zelanda.

Morales, M., R. Barberena, J.B. Belardi, L. Borrero, V. Cortegoso, V. Durán, R. Guerci, A. Goñi, A. Gil, G. Nem, H. Yacobaccio y M. Zárate

2009 Reviewing human-environment interactions in arid regions of southern South America during the past 3000 years, Palaeogeography, Palaeoclimatology, Palaeoecology No 281, (3-4): 283-295, Holanda.

Ortiz, P.E.y J.P. Jayat

2007 Roedores sigmodontinos (Mammalia: Rodentia: Cricetidae) del límite Pleistoceno-Holoceno en el valle de Tafí (Tucumán, Argentina): taxonomía, tafonomía y significación paleoambiental, Ameghiniana No 44 (4): 641-660, Argentina.

Ortiz, P.E. y U.F.J. Pardiñas

2001 Sigmodontinos (Mammalia: Rodentia) del Pleistoceno tardío del valle de Tafí (Tucumán, Argentina): taxonomía, tafonomía y reconstrucción paleoambiental, Ameghiniana No 38 (1): 3-26, Argentina

Ortiz, P.E.; M.C. Madozzo Jaén y J.P. Jayat

2012 Micromammals and paleoenvironments: climatic oscillations in the monte desert of Catamarca (Argentina) during the last two millennia, Journal of Arid Environments, $\mathrm{N}^{\mathrm{o}} 77$ : 103-109. EEUU

Pearsall, D.; K Chandler-Ezell y A. Chandler-Ezell

2004 Maize can Still Be Identified Using Phytoliths: Response to Rovner, Journal of Archaeological Science $N^{\circ}$ 31, Academic Press. Reino Unido.

Quesada, M. y M.A. Korstanje

2010 Cruzando Estructuras: El Espacio Productivo y su Entorno Percibido desde las Prácticas Cotidianas, En: El hábitat prehispánico. Arqueología de la arquitectura y de la construcción del espacio organizado (Albeck, Scattolin y Korstanje Eds): 123-153.

Quesada, M.N. y M. Maloberti

2010 La Expansión de los Espacios Agrícolas. Continuidades en la Construcción del Paisaje Agrario en el Sector Septentrional del Valle de El Bolsón (Siglos I a XV), Trabajo presentado en el Simposio Arqueología y Espacialidad: tendencias teóricometodológicas y su aplicación a la cultura material, XVII Congreso Nacional de Arqueología, Mendoza, Argentina.

Quiroga, L.

2005 Arquitectura de la vivienda prehispánica y colonial. Una perspectiva comparativa en el área valliserrana del noroeste argentino, Actas del Congreso Internacional de Arquitectura vernácula, Universidad Pablo de Olavide, Carmona, España. 2007 Arqueología e Historia del paisaje colonial en el Área Surandina (puna y valles altos. Catamarca, Noroeste de Argentina). II Seminario Internacional de Arqueología. Gabinete de Arqueología, Oficina del Historiador de la Ciudad de La Habana, Cuba.

Quiroga, L. y M.A. Korstanje

2007 Arqueología del campesinado en el valle del Bolsón. Producción y residencia como líneas de análisis para una escala de larga duración. En: El Uso de SIG en la Arqueología Sudamericana, M. Figuerero Torres y A. Izeta eds., B.A.R. International Series. John and Erica Hedges, Oxford, Inglaterra.

Sánchez, J.P.; S. Nava; M. Lareschi; P.E. Ortiz y A.A. Guglielmone 2010 Finding of an Ixodid Tick Inside a Late Holocene Owl Pellet From Northwestern Argentina, Journal of Parasitology, $N^{\circ} 96$ (4): 820-822. EEUU.

Tonni, E.P. y F. Fidalgo

1978 Consideraciones sobre los cambios climáticos durante el Pleistoceno tardío reciente en la provincia de Buenos Aires. Aspectos ecológicos y zoogeográficos relacionados. Ameghiniana $\mathrm{N}^{\circ} 15$ : 235-253 Argentina.

Turner, J.C.M.

1973 Descripción geológica. Laguna Blanca, hoja 11d Escala: 1: 200.000. Vol. 142, 74 pp. Dirección Nacional de Geología y Minería. Buenos Aires, Argentina. 